\title{
Comparison between the Prebolus T1 Measurement and the Fixed T1 Value in Dynamic Contrast-Enhanced MR Imaging for the Differentiation of True Progression from Pseudoprogression in Glioblastoma Treated with Concurrent Radiation Therapy and Temozolomide Chemotherapy
}

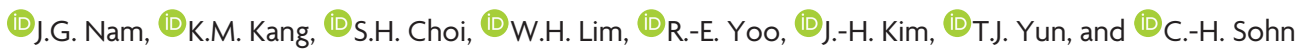

\begin{abstract}
BACKGROUND AND PURPOSE: Glioblastoma is the most common primary brain malignancy and differentiation of true progression from pseudoprogression is clinically important. Our purpose was to compare the diagnostic performance of dynamic contrast-enhanced pharmacokinetic parameters using the fixed $\mathrm{Tl}$ and measured $\mathrm{Tl}$ on differentiating true from pseudoprogression of glioblastoma after chemoradiation with temozolomide.
\end{abstract}

MATERIALS AND METHODS: This retrospective study included 37 patients with histopathologically confirmed glioblastoma with new enhancing lesions after temozolomide chemoradiation defined as true progression $(n=15)$ or pseudoprogression $(n=22)$. Dynamic contrast-enhanced pharmacokinetic parameters, including the volume transfer constant, the rate transfer constant, the blood plasma volume per unit volume, and the extravascular extracellular space per unit volume, were calculated by using both the fixed $\mathrm{Tl}$ of $1000 \mathrm{~ms}$ and measured $\mathrm{T}$ by using the multiple flip-angle method. Intra- and interobserver reproducibility was assessed by using the intraclass correlation coefficient. Dynamic contrast-enhanced pharmacokinetic parameters were compared between the 2 groups by using univariate and multivariate analysis. The diagnostic performance was evaluated by receiver operating characteristic analysis and leave-one-out cross validation.

RESULTS: The intraclass correlation coefficients of all the parameters from both $T 7$ values were fair to excellent (0.689-0.999). The volume transfer constant and rate transfer constant from the fixed $T 7$ were significantly higher in patients with true progression $(P=.048$ and .010 , respectively). Multivariate analysis revealed that the rate transfer constant from the fixed $\mathrm{T} 1$ was the only independent variable $\left(\mathrm{OR}, 1.77 \times 10^{5}\right.$ ) and showed substantial diagnostic power on receiver operating characteristic analysis (area under the curve, $0.752 ; P=$ .002). The sensitivity and specificity on leave-one-out cross validation were $73.3 \%$ (11/15) and 59.1\% (13/20), respectively.

CONCLUSIONS: The dynamic contrast-enhanced parameter of rate transfer constant from the fixed $\mathrm{Tl}$ acted as a preferable marker to differentiate true progression from pseudoprogression.

ABBREVIATIONS: $\mathrm{DCE}=$ dynamic contrast-enhanced; $\mathrm{K}_{\mathrm{ep}}=$ rate transfer constant; $K^{\text {trans }}=$ volume transfer constant; $\mathrm{TMZ}=$ temozolomide; $\mathrm{V}_{\mathrm{p}}=$ the blood plasma volume per unit volume of tissue; $\mathrm{V}_{\mathrm{e}}=$ the extravascular extracellular space per unit volume of tissue; AUC $=$ area under the curve

G lioblastoma is the most common primary brain malignancy, and concurrent chemoradiation with temozolomide (TMZ) after surgical resection is the standardized treatment known to exhibit the best survival for patients. ${ }^{1}$ For the TMZ chemoradiation treatment, the well-known radiologic false progression (so-called "pseudoprogression") has been previously reported to

Received February 23, 2017; accepted after revision July 24

From the Department of Radiology (J.G.N., K.M.K., S.H.C., W.H.L., R.-E.Y., J.-H.K., T.J.Y., C.-H.S.), Seoul National University Hospital, Seoul, Korea; and Center for Nanoparticle Research, Institute for Basic Science (S.H.C., C.-H.S.) and School of Chemical and Biological Engineering (S.H.C.), Seoul National University, Seoul, Korea.

Please address correspondence to Koung Mi Kang, MD, Department of Radiology, Seoul National University Hospital, 101 Daehangno, Jongno-gu, Seoul 110-744,

Korea; e-mail: we3001@gmail.com

http://dx.doi.org/10.3174/ajnr.A5417 appear in approximately $20 \%$ of patients after their first posttreatment MR imaging. ${ }^{2,3}$ This phenomenon is most conspicuous at 12 weeks after chemoradiation therapy and is regarded to result from the transient treatment-induced changes of the capillary and cell membrane permeability, distortion of the BBB, and alterations in cell metabolism. ${ }^{2}$ Because TMZ is one of the few limited treatment options for patients with glioblastoma, revised Response Assessment in Neuro-Oncology criteria accept the radiologic decision of true progression only when the lesion increases in the follow-up imaging after the completion of 6 cycles of adjuvant chemotherapy. ${ }^{4}$ However, in this clinical setting, patients with true progression may suffer from the side effects of ineffective chemotherapy and be deprived of opportunities to pursue alternative treatments such as bevacizumab chemotherapy. Therefore, it is clinically important to distinguish true progres- 


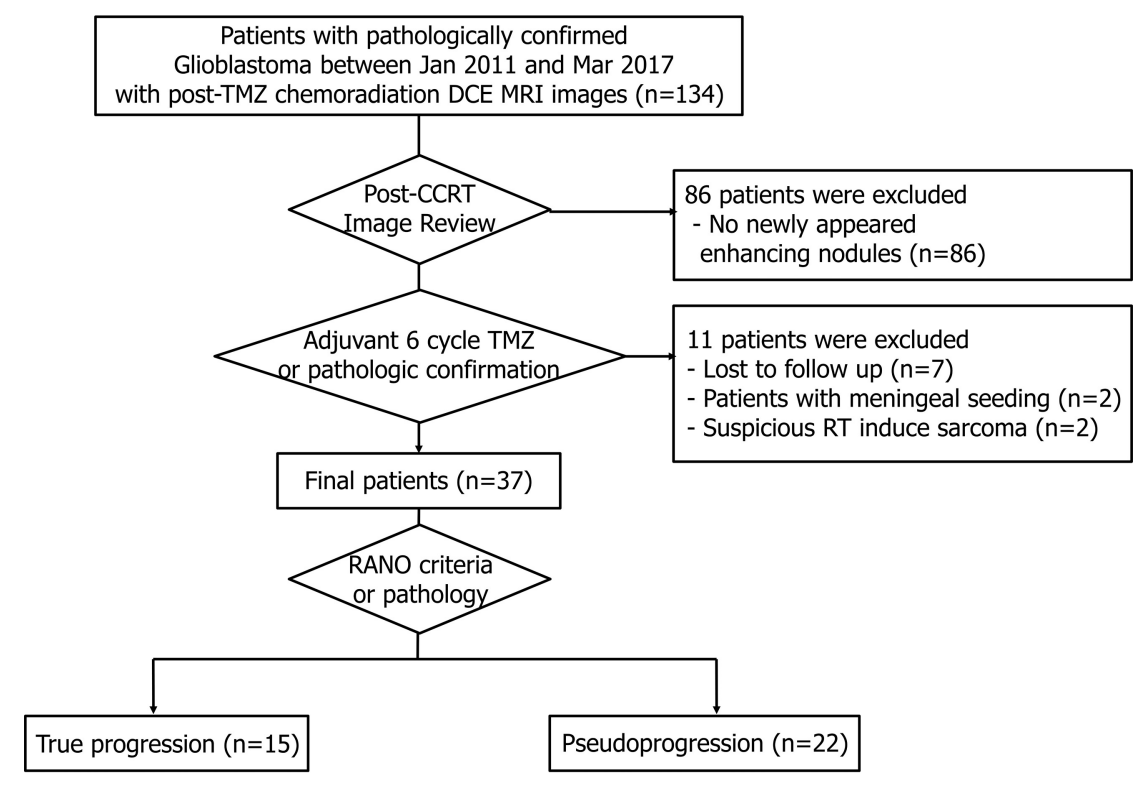

FIG 1. Flowchart of the inclusion and exclusion criteria of our study population.

diagnostic performance of the following 2 methods in calculating the baseline T1: the T1 measurement when using the multiple flip-angle method versus using the fixed $\mathrm{T} 1$ of $1000 \mathrm{~ms}$.

\section{MATERIALS AND METHODS Patients}

The institutional review board of Seoul National University Hospital approved this retrospective study, and the requirement for informed consent was waived. Using a computerized search of the pathology records at our institution and reviewing the electronic medical records, we identified 134 consecutive patients pathologically diagnosed with glioblastoma after either surgical resection or biopsy between January 2011 to March 2017 who met the following criteria: 1) available baseline contrast-enhanced MR imaging performed within 2 sion from pseudoprogression after 12 weeks of chemoradiation before the administration of adjuvant chemotherapy.

There have been continuous efforts to differentiate true progression by using conventional MR imaging techniques with contrast enhancement, DWI, or PWI, ${ }^{5-9}$ but achieving clinically credible differentiation still remains challenging. Dynamic contrast-enhanced (DCE) MR imaging can noninvasively provide pharmacokinetic parameters representing the microcirculation of the tissue; these parameters include the volume transfer constant $\left(K^{\text {trans }}\right)$, the rate transfer constant $\left(K_{e p}\right)$, the blood plasma volume per unit volume of tissue $\left(\mathrm{V}_{\mathrm{e}}\right)$, and the extravascular extracellular space per unit volume of tissue $\left(\mathrm{V}_{\mathrm{p}}\right)$. A few studies reported that some parameters, such as $K^{\text {trans }}$ and $V_{e}$, showed significant differences between true progression and pseudoprogression $^{10,11}$; however, there has been a lack of studies that meticulously explored the diagnostic performance of all DCE parameters in accordance with the prebolus T1 acquisition methods.

To derive the pharmacokinetic parameters from the DCE MR imaging, a prebolus $\mathrm{T} 1$ is required at the initial step to obtain a concentration-time curve. ${ }^{12}$ Between 2 options of the precontrast $\mathrm{T} 1$ value, the measured and the fixed $\mathrm{T} 1$, the baseline $\mathrm{T} 1$ measurement is theoretically the more accurate method reflecting the nature of the tissue. However, the fixed T1 method, less prone to systematic errors resulting from scale factor miscalibration and motion susceptibility, has been reported to be more reliable. ${ }^{12-14}$ Among T1 measurement methods, because of the long acquisition time, standard inversion recovery is prone to systemic error and also is less applicable in routine clinical practice. The multiple flip-angle method is generally regarded as the clinically more applicable method compared with the inversion-recovery method because of its reduced acquisition time and decreased motion artifacts. $^{15,16}$

Therefore, the purpose of this study was to evaluate the value of the pharmacokinetic parameters from DCE MR imaging in differentiating true progression from pseudoprogression of glioblastoma after TMZ chemoradiation as well as to compare the days after surgery or biopsy and 2) underwent DCE MR imaging with multiple flip-angle imaging within 2 months after TMZ chemoradiation therapy. We excluded 86 patients who did not show a newly manifested measurable enhanced area (larger than $10 \mathrm{~mm}$ bidimensionally on MR imaging) in the radiation field on postchemoradiation MR imaging. In addition, 11 patients who were lost to follow-up $(n=7)$, who had a decreased nodule size but developed meningeal seeding during the follow-up $(n=2)$, or whose lesion was suspicious for radiation therapy-induced sarcoma $(n=2)$ were excluded. Finally, 37 patients were included, with a mean age \pm SD of 57.0 years \pm 12.8 years (Fig 1 ). Among them, 5 patients were defined to have true progression (ie, the patient's status was not attributable to concurrent medication or the patient's comorbid conditions were apparent to declare progression on current treatment) according to pathologic confirmation $(n=3)$ or obvious clinical deterioration $(n=2)$. The other 32 patients were classified as having either true progression ( $n=$ $10)$ or pseudoprogression $(n=22)$ radiologically according to the Response Assessment in Neuro-Oncology criteria in consensus of 3 radiologists (J.G.N., K.M.K., and S.H.C.) with 2, 8, and 15 years of experience, respectively. True progression was decided when either there was new enhancement outside the radiation field or the enhancing lesions showed an increase by $\geq 25 \%$ in the sum of the products of the perpendicular diameters on the postadjuvant TMZ chemotherapy scan; otherwise, pseudoprogression was decided. $^{4}$

\section{DCE MR Imaging Acquisition}

All patients underwent follow-up DCE MR imaging studies after the completion of concurrent TMZ chemoradiation with a 3T imaging unit with a 32-channel head coil (Verio; Siemens, Erlangen, Germany $[n=33]$ and Ingenia; Philips Healthcare, Best, the Netherlands $[n=4$, respectively]). The MR imaging included sagittal T1WI and reconstructed transverse and coronal images acquired before and after contrast enhancement with a 3D rapid 
acquisition of gradient-echo sequence and a transverse FLAIR sequence. For the gradient-echo sequence, the following MR parameters were used: TR, $1500 \mathrm{~ms}$; TE, $1.9 \mathrm{~ms}$; flip angle, $9^{\circ}$; and matrix, $256 \times 232$ with an FOV of $220 \times 250$, a section thickness of $1 \mathrm{~mm}$, and 1 acquired signal. For the T1 measurement analysis, additional precontrast images were collected with multiple flip angles of $2^{\circ}, 8^{\circ}$, and $15^{\circ}$ from the spoiled gradient-echo T1WI. Afterward, transverse T2WI with TSE was collected with the following MR parameters: TR, $5160 \mathrm{~ms}$; TE, $91 \mathrm{~ms}$; flip angle, $130^{\circ}$; and matrix, $640 \times 510-580$ with an FOV of $175-199 \times 220$, section thickness of $5 \mathrm{~mm}$, and 3 NEX. Axial FLAIR imaging was performed with the following MR parameters: TR, $9000 \mathrm{~ms}$; TE, $97 \mathrm{~ms}$; flip angle, $130^{\circ}$; and matrix, $384 \times 348$ with an FOV of $199 \times 220$ and a section thickness of $5 \mathrm{~mm}$. Contrast-enhanced imaging was performed after intravenous administration of gadobutrol (Gadovist; Bayer Schering Pharma, Berlin, Germany) at a dose of $0.1 \mathrm{mmol} / \mathrm{L}$ per kilogram of body weight.

DCE MR imaging was performed by using $3 \mathrm{D}$ gradient-echo T1WI after intravenous administration of gadobutrol $(0.1 \mathrm{mmol} /$ $\mathrm{L} / \mathrm{kg}$ ) by using a power injector (Spectris; MedRad, Indianola, Pennsylvania) at a rate of $4 \mathrm{~mL} / \mathrm{s}$. A $30-\mathrm{mL}$ bolus injection of saline followed gadobutrol treatment at the same injection rate. For each section, 40 images were acquired at intervals equal to the TR. The following MR parameters were used: TR, $2.8 \mathrm{~ms}$; TE, 1.0 ms; flip angle, $10^{\circ}$; and matrix, $192 \times 192$ with a section thickness of $3 \mathrm{~mm}$, an FOV of $240 \times 240 \mathrm{~mm}$, a voxel size of $1.25 \times 1.25 \times$ $3 \mathrm{~mm}^{3}$, a pixel bandwidth of $789 \mathrm{~Hz}$, and a total acquisition time of 1 minute 30 seconds.

\section{Image Analysis}

T1 Measurement from the Multiple Flip-Angle Method. DCE MR images were processed by using the MR imaging perfusion analysis method (nordicICE; NordicNeuroLab, Bergen, Norway), and the $3 \mathrm{D}$ gradient-echo T1-weighted images were used. After registering the precontrast acquisitions with the multiple flip-angle images (by using 3 flip angles $\left[2^{\circ}, 8^{\circ}\right.$, and $15^{\circ}$ ] from the spoiled gradient-echo T1-weighted images), the $\mathrm{T} 1$ measurement was automatically calculated by the following equation by using the software (nordicICE):

$$
S=M_{0} \times \frac{\sin \propto \times\left(1-E_{1}\right) \times E_{2}}{1-E_{1} \times \cos \propto}
$$

where $E_{1}=\exp \left(-\mathrm{TR} / \mathrm{T}_{1}\right)$ and $E_{2}=\exp \left(-\mathrm{TE} / \mathrm{T}_{2}^{*}\right),(S=$ signal intensity; $M_{0}=$ the equilibrium magnetization; T1 = longitudinal relaxation; $\mathrm{T}_{2}{ }^{*}=$ effective transverse relaxation; and $\alpha=$ flip angle). As $E_{2}$ is usually ignored when $\mathrm{TE} \ll \mathrm{T}_{2}^{*}$, the equation can be simplified to the following linear form. ${ }^{17-19}$

$$
\frac{S}{\sin \propto}=E_{1} \times \frac{S}{\tan \alpha}+M_{0} \times\left(1-E_{1}\right)
$$

Then, $E_{1}$ and finally T1 maps can be derived by solving multiple equations generated by entering multiple flip angles $\left(2^{\circ}, 8^{\circ}\right.$, and $\left.15^{\circ}\right){ }^{17-19}$

DCE Parameter Acquisition. For each patient, the arterial input function was automatically detected from the software (nordicICE) by analyzing all pixel-time curves in the dataset and applying cluster analysis to select the time courses that most resembled the expected arterial input function properties, satisfying large area under the curve (AUC), low first moment, and high peak enhancement. ${ }^{20}$ The VOI was plotted section by section by using the semiautomatic segmentation method in the pixel analysis software (nordicICE), including all newly developed enhancing areas and excluding vessels and necrotic or liquefied regions. Then, the overall value for each tumor was obtained automatically by the software by summing up all values from each plane.

The pharmacokinetic DCE parameters, including $K^{\text {trans }}, K_{e p}$, blood plasma volume per unit volume of tissue, and extravascular extracellular space per unit volume of tissue, were calculated based on the 2-compartment pharmacokinetics model proposed by Tofts and Kermode. ${ }^{21}$ Each parameter was calculated by using both the measured T1 derived from T1 mapping and the fixed T1 of $1000 \mathrm{~ms}$. Each procedure, including arterial input function selection and VOI plotting, was performed twice for both T1 methods by a radiologist (J.G.N.) at 2-week intervals and once by another radiologist (W.H.L; 3 years of experience). The total image processing for each patient required approximately 4-6 minutes and 8-10 minutes for the fixed T1 and measured T1 methods, respectively, for both observers.

\section{Statistical Analysis}

For comparison of clinical and demographic characteristics, the Student $t$ test and $\chi^{2}$ test were used, as appropriate. The intra- and interobserver reproducibility were assessed by using the intraclass correlation coefficient. We adapted the following guidelines for the intraclass correlation coefficient: excellent, higher than 0.75 ; fair, 0.40-0.75; and poor, less than $0.40 .{ }^{22}$ The KolmogorovSmirnov test was used to determine whether any noncategoric data were normally distributed. The means of the variables were compared between the true progression and pseudoprogression groups by using the Student $t$ test when the data were normally distributed, and the median and ranges of the variables were compared by using the Mann-Whitney $U$ test for variables not normally distributed. Significant variables from the univariate analyses were applied to the multivariate logistic regression analysis. The diagnostic performance was evaluated by receiver operating characteristic analysis; the optimal criterion that maximizes sensitivity and specificity corresponding with the Youden Index J was selected by the software (MedCalc; MedCalc Software, Mariakerke, Belgium). ${ }^{23}$ To compare the diagnostic power of T1 measurement and fixed $\mathrm{T} 1$ methods, a pair-wise comparison receiver operating characteristic curve analysis was used. ${ }^{24}$ Leave-one-out cross-validation was also performed to validate the diagnostic performance.

Statistical analyses were performed by using MedCalc software version 15.8 (MedCalc Software). For all tests, values of $P<.05$ were considered statistically significant.

\section{RESULTS}

As mentioned previously, among 37 patients, 15 were defined as having true progression according to pathologic confirmation $(n=3)$, apparent clinical deterioration $(n=2)$, or radiologic diagnosis following the Response Assessment in Neuro- 


\begin{tabular}{|c|c|c|c|}
\hline Variable & $\begin{array}{l}\text { True Progression } \\
\qquad(n=15)\end{array}$ & $\begin{array}{l}\text { Pseudoprogression } \\
\qquad(n=22)\end{array}$ & $\begin{array}{c}P \\
\text { Value }^{\mathrm{a}}\end{array}$ \\
\hline Age, yr (mean $\pm S D)$ & $59.6 \pm 11.9$ & $56.7 \pm 13.7$ & .61 \\
\hline Gender & & & .12 \\
\hline Male & $9(60.0 \%)$ & $17(77.3 \%)$ & \\
\hline Female & $6(40.0 \%)$ & $5(22.7 \%)$ & \\
\hline Surgery & & & .24 \\
\hline Biopsy & $4(26.7 \%)$ & $2(9.1 \%)$ & \\
\hline Subtotal & $6(40.0 \%)$ & $9(40.9 \%)$ & \\
\hline Total & $5(33.3 \%)$ & $11(50.0 \%)$ & \\
\hline $\begin{array}{l}\text { Time interval of end of TMZ-chemoradiation to DCE MRI, } \\
\quad d \text { (mean } \pm S D \text { [range }] \text { ) }\end{array}$ & $27.0 \pm 7.3[15-44]$ & $28.7 \pm 6.0[17-44]$ & .39 \\
\hline $\begin{array}{l}\text { End of adjuvant TMZ chemotherapy to follow-up MRI, } \\
\qquad d \text { (mean } \pm S D \text { [range]) }\end{array}$ & $31.2 \pm 10.6[20-53]^{b}$ & $26.2 \pm 8.7[16-54]$ & .46 \\
\hline $\begin{array}{l}\text { Initial operation to the last follow-up, } d \text { (mean } \pm \text { SD } \\
\text { [range]) }\end{array}$ & $391.4 \pm 156.3[224-716]$ & $657.3374 .7[274-1774]$ & .002 \\
\hline
\end{tabular}

Table 2: Comparison of the DCE pharmacokinetic parameters of patients with true progression versus pseudoprogression

\begin{tabular}{|c|c|c|c|c|c|c|c|c|}
\hline \multirow{2}{*}{$\begin{array}{l}\text { Pharmacokinetic } \\
\text { Parameter }\end{array}$} & \multirow{2}{*}{$\begin{array}{c}\mathrm{Tl} \\
\text { Method }\end{array}$} & \multicolumn{2}{|c|}{$\begin{array}{l}\text { True Progression } \\
\qquad(n=15)\end{array}$} & \multicolumn{2}{|c|}{$\begin{array}{l}\text { Pseudoprogression } \\
\qquad(n=22)\end{array}$} & \multirow{2}{*}{$\begin{array}{c}P \\
\text { Value }^{\mathrm{a}}\end{array}$} & \multicolumn{2}{|c|}{$\begin{array}{l}\text { Intraclass Correlation } \\
\text { Coefficient }[95 \% \mathrm{CI}]\end{array}$} \\
\hline & & Mean \pm SD & Median [range] & Mean \pm SD & Median [range] & & Intraobserver & Interobserver \\
\hline \multirow[t]{2}{*}{$K^{\text {trans }}, \min ^{-1}$} & Fixed & $0.138 \pm 0.148$ & $0.096[0.042-0.579]$ & $0.068 \pm 0.043$ & $0.064[0.0005-0.154]$ & $.05^{\mathrm{b}}$ & $0.893[0.792-0.945]$ & $0.897[0.799-0.947]$ \\
\hline & Measured & $0.126 \pm 0.139$ & $0.069[0.025-0.499]$ & $0.056 \pm 0.045$ & $0.058[0.0001-0.194]$ & .10 & $0.923[0.850-0.960]$ & $0.943[0.888-0.970]$ \\
\hline \multirow[t]{2}{*}{$\mathrm{K}_{\mathrm{ep}}, \min ^{-1}$} & Fixed & $0.321 \pm 0.244$ & $0.244[0.135-1.082]$ & $0.179 \pm 0.103$ & $0.179[0.024-0.483]$ & $.01^{\mathrm{b}}$ & $0.910[0.825-0.954]$ & $0.929[0.862-0.963]$ \\
\hline & Measured & $0.224 \pm 0.108$ & $0.202[0.035-0.396]$ & $0.192 \pm 0.148$ & $0.157[0.009-0.494]$ & .47 & $0.861[0.729-0.928]$ & $0.882[0.771-0.939]$ \\
\hline \multirow[t]{2}{*}{$v_{p}, \%$} & Fixed & $3.309 \pm 4.429$ & $1.468[0.709-18.298]$ & $1.998 \pm 1.462$ & $1.705[0.140-6.723]$ & .60 & $0.872[0.752-0.934]$ & $0.888[0.784-0.943]$ \\
\hline & Measured & $2.358 \pm 2.701$ & $1.339[0.478-10.407]$ & $1.521 \pm 1.456$ & $1.134[0.081-6.056]$ & .27 & $0.800[0.605-0.895]$ & $0.688[0.394-0.839]$ \\
\hline \multirow[t]{2}{*}{$v_{e}$} & Fixed & $0.536 \pm 0.330$ & $0.446[0.168-1.050]$ & $0.506 \pm 0.284$ & $0.482[0.114-1.156]$ & .77 & $0.761[0.537-0.877]$ & $0.718[0.516-0.844]$ \\
\hline & Measured & $0.550 \pm 0.511$ & $0.377[0.121-1.192]$ & $0.316 \pm 0.265$ & $0.270[0.041-1.297]$ & .08 & $0.937[0.877-0.968]$ & $0.936[0.875-0.967]$ \\
\hline
\end{tabular}

a $P$ values are from Student $t$ test when the variables satisfied normality $\left(K_{\text {ep }}\right.$ from measured $T I$ and $V_{e}$ from fixed $\left.T 1\right)$ or from Mann-Whitney $U$ tests otherwise, according to Kolmogorov-Smirnov test.

${ }^{\mathrm{b}}$ Significant $P$ value for each test.

Oncology criteria $(n=10){ }^{4}$ The other 22 patients were defined as having pseudoprogression.

Among the patients, $73.3 \%$ (11/15) of the true progression patients and $90.9 \%(20 / 22)$ of the pseudoprogression patients underwent radical surgery, whereas the others underwent stereotactic biopsy. The immediate postoperative MR imaging showed that total resection was achieved for $45.5 \%(5 / 11)$ and $55.0 \%(11 / 20)$ of surgical cases in the true progression and pseudoprogression groups, respectively. Detailed demographics are listed in Table 1.

\section{Intraobserver and Interobserver Reproducibility of DCE Pharmacokinetic Parameters}

The intraclass correlation coefficients for intra- and interobserver agreement for each DCE pharmacokinetic parameter were deemed mostly excellent, or at least fair, ranging from $0.689-0.943,{ }^{22}$ for both the fixed $\mathrm{T} 1$ and measured $\mathrm{T} 1$ methods (Table 2).

\section{Comparison of DCE Pharmacokinetic Parameters: True Progression versus Pseudoprogression}

Among the 4 DCE pharmacokinetic parameters calculated from the 2 different precontrast T1 values, the mean value was compared for the 2 parameters that satisfied normality based on the Kolmogorov-Smirnov test: $\mathrm{K}_{\mathrm{ep}}$ from the measured $\mathrm{T} 1$ and $\mathrm{V}_{\mathrm{e}}$ from the fixed T1. The median and ranges for the other 6 parameters were compared. Only 2 parameters showed a significant dif- ference between the true progression and pseudoprogression groups: $K^{\text {trans }}$ evaluated from the fixed T1 (median [range] value of true progression versus pseudoprogression, 0.096 minutes $^{-1}$ [0.042-0.580] versus 0.064 minutes $\left.^{-1}[0.0005-0.154] ; P=.048\right)$ and $\mathrm{K}_{\mathrm{ep}}$ calculated from the fixed $\mathrm{T} 1$ (median [range], $0.244 \mathrm{~min}-$ utes $^{-1}$ [0.135-1.082] versus 0.179 minutes $^{-1}$ [0.024-0.483]; $P=$ $.010)$. No parameters obtained from the measured T1 showed significant difference between the 2 groups (Table 2). The representative cases are presented in Figs 2 and 3.

The multivariate logistic regression analysis with the backward method was conducted for 3 variables, including significant variables on the univariate analysis $\left(K^{\text {trans }}\right.$ and $K_{\mathrm{ep}}$ evaluated from the fixed $\mathrm{T} 1$ ) and $\mathrm{V}_{\mathrm{e}}$ calculated from the fixed $\mathrm{T} 1$ method, which was shown to exhibit significant difference in the previous study. ${ }^{10}$ As a result, $\mathrm{K}_{\mathrm{ep}}$ from the fixed $\mathrm{T} 1$ method was the only significant parameter (OR [95\% CI], $1.77 \times 10^{5}\left[4.27-7.32 \times 10^{9}\right] ; P=$ $.007)$.

\section{Diagnostic Performance of DCE Pharmacokinetic Parameters: Comparison of the Fixed T1 and T1 Measurement Methods}

In the receiver operating characteristic analysis, $K^{\text {trans }}$ and $K_{\text {ep }}$ from the fixed $\mathrm{T} 1$ showed significant diagnostic power in distinguishing true progression from pseudoprogression (AUC, 0.694 and $0.752 ; P=.03$ and .002 , respectively). The 2 parameters did not demonstrate a significant difference based on a comparison of 


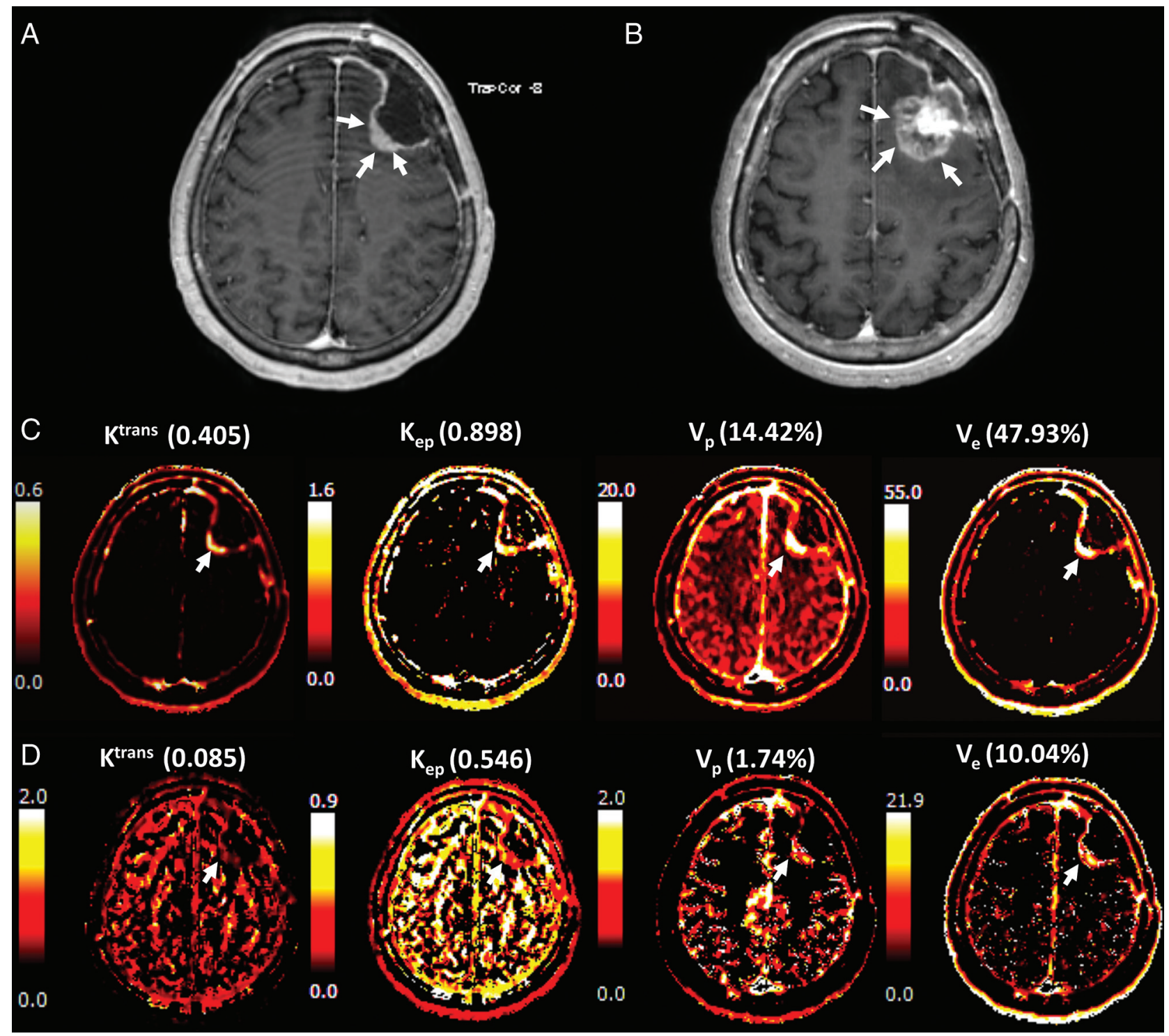

FIG 2. A 68-year-old female patient with surgically proved glioblastoma presented $A$, a newly appeared enhancing nodule on DCE-MR imaging taken 1 month after temozolomide chemoradiation. The lesion was not identified on the postoperative MR imaging. $B$, The lesion was markedly increased after 6 cycles of temozolomide chemotherapy, implying that the lesion was true progression according to the Response Assessment in Neuro-Oncology criteria. The pharmacokinetic DCE maps, especially those for $K^{\text {trans }}$ and $K_{\text {ep }}$, showed a bright signal from both the $C$, fixed TI and $D$, measured $T 1$ methods.

the receiver operating characteristic analysis $(P=.29)$. No parameters obtained from the measured $\mathrm{T} 1 \mathrm{method}$ showed a proper diagnostic performance (all $P \mathrm{~s}>.05$ ).

The diagnostic accuracy of $K^{\text {trans }}$ and $\mathrm{K}_{\mathrm{ep}}$ from the fixed $\mathrm{T} 1$ was $73.0 \%(27 / 37)$ and $70.3 \%(26 / 37)$, respectively. Whereas $K^{\text {trans }}$ from the fixed T1 exhibited high specificity (86.4\%; [19/ 22]) but suboptimal sensitivity $(53.3 \%[8 / 15]), K_{e p}$ from the fixed $\mathrm{T} 1$ showed relatively reliable sensitivity and specificity $(80.0 \%$ [12/15] and 63.6\% [14/22], respectively), along with fair positive predictive value $(60.0 \%,[12 / 20])$ and reliable negative predictive value $(82.4 \%$ [14/17]) (Table 3). The leave-one-out cross-validation for $\mathrm{K}_{\mathrm{ep}}$ from the fixed $\mathrm{T} 1$ method demonstrated similar results: sensitivity, specificity, accuracy, and positive and negative predictive values of $73.3 \%$ (11/15), 59.1\% (13/22), 64.9\% (24/37), $55.0 \%(11 / 20)$, and $76.5 \%(13 / 17)$, respectively (Table 4$)$.

\section{DISCUSSION}

In our study, some pharmacokinetic parameters of the fixed T1 method derived from post-TMZ chemoradiation DCE MR imaging showed a significant difference between the true progression and pseudoprogression groups: $K^{\text {trans }}$ and $K_{\text {ep }}$ from the fixed $\mathrm{T} 1$ were significantly larger in the true progression group than in the pseudoprogression group. No parameters calculated from the measured T1 method demonstrated a significant difference between the 2 groups. In the multivariate analysis, $\mathrm{K}_{\mathrm{ep}}$ from the fixed T1 method was the only significant variable. It exhibited a fair diagnostic performance with acceptable intra- and interobserver reproducibility, especially in terms of sensitivity and negative predictive value, in both the AUC analysis and leave-one-out cross-validation.

Although the baseline T1 measurement provides the tissue 


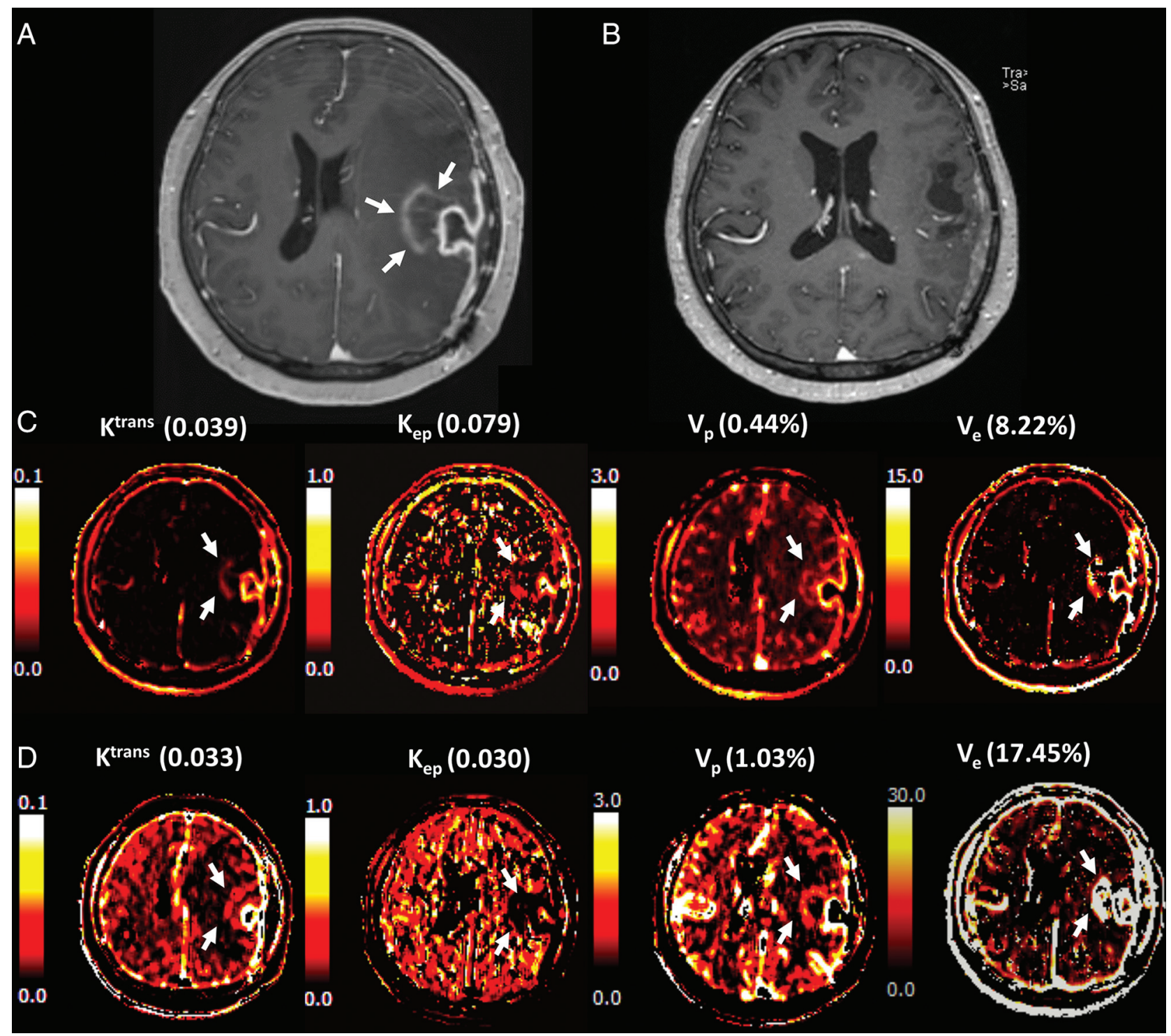

FIG 3. A 57-year-old female patient with surgically proved glioblastoma presented $A$, a newly appeared enhancing nodule on DCE-MR imaging taken 1 month after temozolomide chemoradiation. $B$, The lesion had disappeared after 6 cycles of temozolomide chemotherapy, defining the lesion as a pseudoprogression according to the Response Assessment in Neuro-Oncology criteria. The pharmacokinetic DCE maps, especially those for $K^{\text {trans }}$ and $K_{\mathrm{ep}}$, showed less intense signals from both $C$, the fixed $\mathrm{Tl}$ and $D$, measured $\mathrm{Tl}$ methods.

\section{Table 3: Diagnostic performance of the DCE pharmacokinetic parameters in detecting true progression}

\begin{tabular}{|c|c|c|c|c|c|c|}
\hline $\begin{array}{l}\text { Pharmacokinetic } \\
\text { Parameter }\end{array}$ & $\begin{array}{c}\text { T1 } \\
\text { Method }\end{array}$ & $\begin{array}{c}\text { Median } \\
\text { AUC }\end{array}$ & $\begin{array}{c}\text { Optimal } \\
\text { Threshold } \\
\text { Value }\end{array}$ & Sensitivity [\%] & Specificity [\%] & $\begin{array}{c}P \\
\text { Value }^{\mathrm{a}}\end{array}$ \\
\hline \multirow[t]{2}{*}{$K^{\text {trans }}, \min ^{-1}$} & Fixed & 0.694 & 0.093 & 53.3 & 86.4 & $.03^{\mathrm{b}}$ \\
\hline & Measured & 0.664 & 0.059 & & & .08 \\
\hline \multirow[t]{2}{*}{$\mathrm{K}_{\mathrm{ep}}, \min ^{-1}$} & Fixed & 0.752 & 0.184 & 80.0 & 63.6 & $.002^{\mathrm{b}}$ \\
\hline & Measured & 0.603 & 0.159 & & & .28 \\
\hline \multirow[t]{2}{*}{$v_{p}, \%$} & Fixed & 0.552 & 3.423 & & & .62 \\
\hline & Measured & 0.609 & 0.597 & & & .25 \\
\hline \multirow[t]{2}{*}{$\mathrm{v}_{\mathrm{e}}$} & Fixed & 0.518 & 0.349 & & & .86 \\
\hline & Measured & 0.606 & 0.546 & & & .30 \\
\hline
\end{tabular}

Note: $-V_{\mathrm{e}}$ indicates extravascular extracellular space per unit volume; $\mathrm{V}_{\mathrm{p}}$, blood plasma volume per unit volume.

a $P$ values are from the receiver operating characteristics analysis.

${ }^{\mathrm{b}}$ Significant $P$ value for each test.

property, it has the problem of weak reliability and reproducibility because of major systematic errors resulting from scale factor miscalibration and susceptibility to motion. ${ }^{12,25}$ Because signal artifacts are known to be particularly important in the overall errors of DCE MR imaging among other tissue- or acquisitionrelated parameters, ${ }^{13}$ the fixed $\mathrm{T} 1$, simple and reproducible, has 
Table 4: Diagnostic performance of $K_{e p}$ from the fixed $\mathrm{Tl}$ and results from the leave-one-out cross-validation

\begin{tabular}{lcccccc}
\hline \multicolumn{1}{c}{ Median AUC } & $\begin{array}{c}\text { Optimal } \\
\text { Threshold Value }\end{array}$ & Sensitivity & Specificity & Accuracy & $\begin{array}{c}\text { Positive } \\
\text { Predictive Value }\end{array}$ & $\begin{array}{c}\text { Pegative } \\
\text { Predictive Value }\end{array}$ \\
\hline 0.752 & 0.184 & $80.0 \%(12 / 15)$ & $63.6 \%(14 / 22)$ & $70.3 \%(26 / 37)$ & $60.0 \%(12 / 20)$ & $82.4 \%(14 / 17)$ \\
Leave-one-out & & $73.3 \%(11 / 15)$ & $59.1 \%(13 / 22)$ & $64.9 \%(24 / 37)$ & $55.0 \%(11 / 20)$ & $76.5 \%(13 / 17)$ \\
$\quad$ cross-validation & & & & & & \\
\hline
\end{tabular}

its strength. In this situation, it is necessary to compare the diagnostic performance of DCE parameters from the fixed T1 with measured T1 methods to verify the better processing method. Our study demonstrated that the fixed T1 method more reliably predicts true progression from pseudoprogression. Clinically, our results can provide evidence to eliminate the T1 measurement process in DCE MR interpretation, possibly resulting in the reduction of both imaging acquisition time and postprocessing time.

The use of DCE MR imaging in differentiating true progression from pseudoprogression is in its infancy, and few studies have been performed. Yun et $\mathrm{al}^{10}$ reported that the mean $K^{\text {trans }}$ from the fixed $\mathrm{T} 1$ method is the most convincing parameter in differentiating true progression, but $\mathrm{K}_{\mathrm{ep}}$ was not evaluated. Our study agrees with a previous study reporting that the mean $K^{\text {trans }}$ from the fixed $\mathrm{T} 1$ method was significantly different between true progression and pseudoprogression with similar sensitivity and specificity. ${ }^{10}$ However, the multivariate analysis in our study revealed that $\mathrm{K}_{\mathrm{ep}}$ was the only independently differentiable parameter. To the best of our knowledge, there are no studies that have reported the difference of $\mathrm{K}_{\mathrm{ep}}$ between the 2 groups.

Although both pseudoprogression and true progression appear as new enhancing lesions on the post-TMZ chemoradiation therapy MR imaging, the pathologies are markedly dissimilar. It has been well known that pseudoprogression histopathologically resembles radiation necrosis. ${ }^{3,26}$ Radiation-induced endothelial injury is understood to be the major cause of radiation injury, including pseudoprogression, resulting in destruction of the BBB concomitant with vasogenic edema and tissue ischemia. ${ }^{26,27} \mathrm{Be}-$ cause angiogenesis in addition to breakdown of the BBB occurs for true progression, vascularity-related parameters, including $K^{\text {trans }}$ and $K_{\text {ep }}$, are likely to be higher in true progression than in pseudoprogression. ${ }^{28-30}$

The exchange rate constant $\mathrm{K}_{\mathrm{ep}}$ is a composite parameter of $K^{\text {trans }} / \mathrm{V}_{\mathrm{e}}$ and represents the transit between the extravascular and the intravascular compartments. $\mathrm{K}_{\mathrm{ep}}$ is known to reflect the vessel permeability and the surface area, ${ }^{31}$ both of which are known to be increased in true progression. There have been other reports in other organs that indicated $\mathrm{K}_{\mathrm{ep}}$ as a potential parameter for predicting tumor angiogenesis: $\mathrm{K}_{\mathrm{ep}}$ showed a significant correlation with the microvessel attenuation calculated from immunohistochemistry in prostate cancer, ${ }^{32,33}$ whereas other parameters, including $K^{\text {trans }}, \mathrm{V}_{\mathrm{p}}$, and $\mathrm{V}_{\mathrm{e}}$, did not demonstrate a significant correlation. ${ }^{33}$ A similar study of multiple myeloma also reported that $\mathrm{K}_{\mathrm{ep}}$ was significantly higher in tumors with a high vessel attenuation. ${ }^{34}$ Other reports showed that $\mathrm{K}_{\mathrm{ep}}$ was the only significant DCE parameter (along with $K^{\text {trans }}$ and $\mathrm{V}_{\mathrm{e}}$ ) that was correlated with the histologic grade in rectal cancer and correlated with poor response in malignant pleural mesothelioma. ${ }^{35,36}$ In agreement with the previous explanation, ${ }^{33}$ because it is a composite of 2 parameters, the compounding effects of these parameters might subside and allow $\mathrm{K}_{\mathrm{ep}}$ to present a better correlation with the nature of the lesion.

Our study has some limitations. First, because of its retrospective nature, patients had variable time intervals between treatment and imaging. We selected patients who satisfied Response Assessment in Neuro-Oncology criteria to define the nature of the lesion; thus, some patients with true progression of an aggressive nature might have not been selected because they could not survive 6 cycles of adjuvant chemotherapy. However, because DCE MR imaging was routinely performed at our hospital for patients with glioblastoma with TMZ chemoradiation, our cohort might work as a potentially representative selection. Second, our sample size was small, and the number of tumor types was disproportionate (15 true progression patients and 22 pseudoprogression patients). Third, we did not compare our arterial input function acquisition method with other patient-specific methods or population-based arterial input function, which can reduce both image processing and postprocessing time. Because DCE parameters can also be affected by various arterial input function calculations, further study is recommended for robust arterial input function calculation. In addition, despite previous studies suggesting the reliability of the multiple flip-angle method, further validation of the method compared with the inversion-recovery method should be needed. Finally, we did not compare the diagnostic power of our values with other MR imaging modalities that are reported to be able to differentiate true progression from pseudoprogression, such as ADC or dynamic susceptibility contrast-enhanced MR imaging. ${ }^{5-9}$

\section{CONCLUSIONS}

The semiquantitative DCE-derived parameter $\mathrm{K}_{\mathrm{ep}}$ based on the fixed $\mathrm{T} 1$ value is a preferable marker to differentiate true progression from pseudoprogression versus other parameters derived from tissue T1 measurement.

\section{REFERENCES}

1. Stupp R, Hegi ME, Gorlia T, et al. Cilengitide combined with standard treatment for patients with newly diagnosed glioblastoma with methylated MGMT promoter (CENTRIC EORTC 2607122072 study): a multicentre, randomised, open-label, phase 3 trial. Lancet Oncol 2014;15:1100-08 CrossRef Medline

2. Brandsma D, Stalpers L, Taal W, et al. Clinical features, mechanisms, and management of pseudoprogression in malignant gliomas. Lancet Oncol 2008;9:453-61 CrossRef Medline

3. Chaskis C, Neyns B, Michotte A, et al. Pseudoprogression after radiotherapy with concurrent temozolomide for high-grade glioma: clinical observations and working recommendations. Surg Neurol 2009;72:423-28 CrossRef Medline

4. Wen PY, Macdonald DR, Reardon DA, et al. Updated response assessment criteria for high-grade gliomas: Response Assessment in

AJNR Am J Neuroradiol 38:2243-50 Dec 2017 www.ajnr.org

2249 
Neuro-Oncology working group. J Clin Oncol 2010;28:1963-72 CrossRef Medline

5. Baek HJ, Kim HS, Kim N, et al. Percent change of perfusion skewness and kurtosis: a potential imaging biomarker for early treatment response in patients with newly diagnosed glioblastomas. $R a-$ diology 2012;264:834-43 CrossRef Medline

6. Chen X, Wei X, Zhang Z, et al. Differentiation of true-progression from pseudoprogression in glioblastoma treated with radiation therapy and concomitant temozolomide by GLCM texture analysis of conventional MRI. Clin Imaging 2015;39:775-80 CrossRef Medline

7. Choi YJ, Kim HS, Jahng GH, et al. Pseudoprogression in patients with glioblastoma: added value of arterial spin labeling to dynamic susceptibility contrast perfusion MR imaging. Acta Radiol 2013;54: 448-54 CrossRef Medline

8. Song YS, Choi SH, Park CK, et al. True progression versus pseudoprogression in the treatment of glioblastomas: a comparison study of normalized cerebral blood volume and apparent diffusion coefficient by histogram analysis. Korean J Radiol 2013;14:662-72 CrossRef Medline

9. Chu HH, Choi SH, Ryoo I, et al. Differentiation of true progression from pseudoprogression in glioblastoma treated with radiation therapy and concomitant temozolomide: comparison study of standard and high-b-value diffusion-weighted imaging. Radiology 2013;269:831-40 CrossRef Medline

10. Yun TJ, Park CK, Kim TM, et al. Glioblastoma treated with concurrent radiation therapy and temozolomide chemotherapy: differentiation of true progression from pseudoprogression with quantitative dynamic contrast-enhanced MR imaging. Radiology 2015;274: 830-40 CrossRef Medline

11. Thomas AA, Arevalo-Perez J, Kaley T, et al. Dynamic contrast enhanced T1 MRI perfusion differentiates pseudoprogression from recurrent glioblastoma. J Neurooncol 2015;125:183-90 CrossRef Medline

12. Tietze A, Mouridsen K, Mikkelsen IK. The impact of reliable prebolus $\mathrm{T} 1$ measurements or a fixed $\mathrm{T} 1$ value in the assessment of glioma patients with dynamic contrast enhancing MRI. Neuroradiology 2015;57:561-72 CrossRef Medline

13. Dale BM, Jesberger JA, Lewin JS, et al. Determining and optimizing the precision of quantitative measurements of perfusion from dynamic contrast enhanced MRI. J Magn Reson Imaging 2003;18: 575-84 CrossRef Medline

14. Walker-Samuel S, Parker CC, Leach MO, et al. Reproducibility of reference tissue quantification of dynamic contrast-enhanced data: comparison with a fixed vascular input function. Phys Med Biol 2007;52:75-89 CrossRef Medline

15. Mikkelsen IK, Peters DA, Tietze A. DCE-PWI 3D T1-measurement as function of time or flip angle. In: Proceedings of the International Society for Magnetic Resonance in Medicine 20th Annual Meeting and Exhibition, Melbourne, Australia. May 5-11, 2012

16. Studler U, White LM, Andreisek G, et al. Impact of motion on T1 mapping acquired with inversion recovery fast spin echo and rapid spoiled gradient recalled-echo pulse sequences for delayed gadolinium-enhanced MRI of cartilage (dGEMRIC) in volunteers. J Magn Reson Imaging 2010;32:394-98 CrossRef Medline

17. Li Z, Sun J, Hu X, et al. Assessment of liver fibrosis by variable flip angle T1 mapping at 3.0T. J Magn Reson Imaging 2016;43:698-703 CrossRef Medline

18. Deoni SC, Rutt BK, Peters TM. Rapid combined T1 and T2 mapping using gradient recalled acquisition in the steady state. Magn Reson Med 2003;49:515-26 CrossRef Medline

19. Blüml S, Schad LR, Stepanow B, et al. Spin-lattice relaxation time measurement by means of a TurboFLASH technique. Magn Reson Med 1993;30:289-95 CrossRef Medline
20. Mouridsen K, Christensen S, Gyldensted L, et al. Automatic selection of arterial input function using cluster analysis. Magn Reson Med 2006;55:524-31 CrossRef Medline

21. Tofts PS, Kermode AG. Measurement of the blood-brain barrier permeability and leakage space using dynamic MR imaging. 1. Fundamental concepts. Magn Reson Med 1991;17:357-67 CrossRef Medline

22. Kang KM, Lee JM, Yoon JH, et al. Intravoxel incoherent motion diffusion-weighted MR imaging for characterization of focal pancreatic lesions. Radiology 2014;270:444-53 CrossRef Medline

23. Youden WJ. Index for rating diagnostic tests. Cancer 1950;3:32-35 Medline

24. DeLong ER, DeLong DM, Clarke-Pearson DL. Comparing the areas under two or more correlated receiver operating characteristic curves: a nonparametric approach. Biometrics 1988:837-45 CrossRef Medline

25. Haacke EM, Filleti CL, Gattu R, et al. New algorithm for quantifying vascular changes in dynamic contrast-enhanced MRI independent of absolute T1 values. Magn Reson Med 2007;58:463-72 CrossRef Medline

26. Motegi $\mathrm{H}$, Kamoshima Y, Terasaka S, et al. IDH1 mutation as a potential novel biomarker for distinguishing pseudoprogression from true progression in patients with glioblastoma treated with temozolomide and radiotherapy. Brain Tumor Pathol 2013;30:67-72 CrossRef Medline

27. Wong CS, Van der Kogel AJ. Mechanisms of radiation injury to the central nervous system: implications for neuroprotection. Mol Interv 2004;4:273-84 CrossRef Medline

28. Sugahara T, Korogi Y, Kochi M, et al. Correlation of MR imagingdetermined cerebral blood volume maps with histologic and angiographic determination of vascularity of gliomas. AJR Am J Roentgenol 1998;171:1479-86 CrossRef Medline

29. Oh BC, Pagnini PG, Wang MY, et al. Stereotactic radiosurgery: adjacent tissue injury and response after high-dose single fraction radiation: Part I-Histology, imaging, and molecular events. Neurosurgery 2007;60:31-44; discussion 44-45 CrossRef Medline

30. Tofts PS. T1-weighted DCE imaging concepts: modelling, acquisition and analysis. MAGNETOM Flash 2010;3:30-39

31. Heverhagen JT, von Tengg-Kobligk H, Baudendistel KT, et al. Benign prostate hyperplasia: evaluation of treatment response with DCE MRI. MAGMA 2004;17:5-11 CrossRef Medline

32. Schlemmer HP, Merkle J, Grobholz R, et al. Can pre-operative contrast-enhanced dynamic MR imaging for prostate cancer predict microvessel density in prostatectomy specimens? Eur Radiol 2004; 14:309-17 CrossRef Medline

33. Oto A, Yang C, Kayhan A, et al. Diffusion-weighted and dynamic contrast-enhanced MRI of prostate cancer: correlation of quantitative MR parameters with Gleason score and tumor angiogenesis. AJR Am J Roentgenol 2011;197:1382-90 CrossRef Medline

34. Nosàs-Garcia S, Moehler T, Wasser K, et al. Dynamic contrast-enhanced MRI for assessing the disease activity of multiple myeloma: a comparative study with histology and clinical markers. J Magn Reson Imaging 2005;22:154-62 CrossRef Medline

35. Yao WW, Zhang H, Ding B, et al. Rectal cancer: 3D dynamic contrast-enhanced MRI; correlation with microvascular density and clinicopathological features. Radiol Med 2011;116:366-74 CrossRef Medline

36. Giesel FL, Bischoff H, von Tengg-Kobligk H, et al. Dynamic contrastenhanced MRI of malignant pleural mesothelioma: a feasibility study of noninvasive assessment, therapeutic follow-up, and possible predictor of improved outcome. Chest 2006;129: 1570-76 CrossRef Medline 